\title{
Arbor
}

\section{La Audiencia Nacional}

\section{Javier Puyol Montero}

Arbor CLXXV, 691 (Julio 2003), 1287-1293 pp.

La existencia de la Audiencia Nacional se justifica desde la óptica de la seguridad jurídica de los ciudadanos, que constituye la piedra angular del estado de derecho.

Para ello, tal como se expone en la Exposición de Motivos del Real Decreto-Ley 1/1977, de 4 de enero, por el que se crea la Audiencia Nacional, la obtención de tal objetivo debe partir de la existencia de una Administración de Justicia que sea independiente, técnicamente objetivada $\mathrm{y}$, además, que sea formalmente adecuada en el ejercicio de su función para asegurar un proceso pleno de garantías y una decisión judicial pronta y justa. En este sentido, debe recalcarse que en su origen se trató de conjugar tanto la existencia de una Justicia rápida y eficaz, sin que ello hiciera disminuir, ni conculcara ni las garantías procesales, ni de índole fundamental que deben presidir los todos procedimiento judicial, especialmente aquellos propios de la jurisdicción penal.

Esta situación viene además muy influida, por lo que la aludida Exposición de Motivos denominada como «las condiciones de la vida moderna", las cuales se encuentran íntimamente vinculadas con la aparición de una nueva y compleja delincuencia, que no sólo ha producido el nacimiento de nuevas y más sofisticadas figuras delictivas que sin lugar a dudas se encuentran en relación directa con el propio desenvolvimiento de la sociedad, y el desarrollo técnico y tecnológico que se está produciendo en la misma.

En este sentido la indicada Exposición de Motivos señala: «la moderna sociedad industrial, cuyas características ha incorporado España en los últimos decenios con éxito innegable, sufre la proliferación de 
nuevos modos de delincuencia, de extensión e intensidad desconocidas hasta hace poco tiempo.

El trafico organizado de moneda, drogas y estupefacientes, la existencia de grupos que, bajo apariencias de seriedad empresarial, defraudan a una pluralidad de personas, los supuestos especialmente nocivos de fraudes alimenticios o de sustancias farmacéuticas o medicinales con efectos lesivos dispersos en diversas zonas del territorio nacional, son ejemplos bien expresivos, entre otros posibles, de modalidades delictivas para cuya investigación y enjuiciamiento resulta inadecuada una administración de justicia organizada en juzgados y audiencias de competencia territorial limitada».

De ello surge la necesidad de la creación y construcción de órganos judiciales que insertos en el ámbito de la jurisdicción ordinaria, puedan dedicarse, como antes quedó dicho, con plenitud de garantías para el ciudadano y la sociedad, al conocimiento de este tipo de delitos.

Complementariamente y desde una perspectiva estrictamente administrativa debe resaltarse la potenciación que en nuestros días está sufriendo la Administración, que desde el punto de vista judicial está produciendo una multiplicación de los supuestos de revisión jurisdiccional, en perjuicio de las exigencias mismas que determina un correcto funcionamiento de la Administración de Justicia.

La Audiencia Nacional se creó respondiendo al propósito de abordar la solución de tales problemas, basada en el modelo tradicional de la «Audiencia», como órgano colegiado de la Administración de Justicia, diferenciándose fundamentalmente en su ámbito jurisdiccional desde el punto de vista del territorio al ejercer su función a la totalidad del ámbito nacional. El ejercicio de esta función jurisdiccional está en íntima conexión con las funciones de índole material que la misma está llamada a desempeñar, que no son otras más que las siguientes; sin perjuicio de lo que más adelante se dirá:

a) En lo penal, el conocimiento de los delitos en que por el modo y el ámbito de actuación de sus autores o por la difusión de sus efectos se exceden los limites territorial de una provincia;

b) En lo contencioso-administrativo, la revisión de actos emanados de autoridades administrativas con competencia sobre todo el territorio nacional.

Tanto con la creación de la Audiencia Nacional, como de los Juzgados Centrales de Instrucción se trataba de satisfacer las exigencias contempladas en el artículo 304 de la Ley de Enjuiciamiento Criminal, el cual permite el nombramiento de jueces instructores especiales en 


\section{La Audiencia Nacional}

determinados supuestos, relativos a delitos cuyas extraordinarias circunstancias o las de lugar y tiempo de su ejecución o de las personas que en ellos hubieran intervenido como ofensores $u$ ofendidos, lo requieran para la mas acertada investigación y la mas segura comprobación de los hechos.

En la organización interna de esta nueva estructura judicial, y desde la perspectiva de las exigencias de un sereno e imparcial enjuiciamiento, existían dos oportunidades para el legislador, por un lado la posibilidad de hacer una enumeración casuística de los supuestos concretos en los que presumiblemente iban a incidir las circunstancias y requisitos que se contemplaban el citado articulo 304 de la Ley de Enjuiciamiento Criminal, o establecer una formula suficientemente amplia y flexible para que pudiera abarcar todos los casos que la finalidad de su creación quería incluir, dejando a la prudente decisión de los propios Tribunales de Justicia la importantísima función de acordar en cada caso lo procedente. Sin embargo, finalmente, ha sido una tercera vía, de carácter mixto, la que fue finalmente la seguida, en el sentido señalado por la citada Exposición de Motivos, consistente en que:

A) Por una parte, se enunciaron una serie de delitos cuya naturaleza entraña ya de por si la concurrencia de las características generales que definen la competencia de la audiencia nacional y;

B) Por otra, se utilizó una expresión genérica comprensiva de todos los demás casos en los que, por razón de su extraordinaria complejidad o de sus graves efectos en el ámbito nacional, dando la posibilidad a que la Sala de Gobierno del Tribunal Supremo procediera al nombramiento de juez especial, que, había de recaer en uno de los jueces centrales de instrucción.

También debe resaltarse que la creación de la Audiencia Nacional implicó la desaparición de la jurisdicción especial administrativa de delitos monetarios que hasta ese momento existente, al estimarse que la mayor eficacia en la defensa de la sociedad y la mejor garantía ciudadana exigían el conocimiento y el pleno sometimiento de dichos asuntos por la jurisdicción ordinaria. En este mismo sentido se estimó era razonable atribuir a la indicada Audiencia Nacional el conocimiento de los casos de extradición pasiva, basada fundamentalmente en el hecho notorio de la mayor intensidad de la cooperación jurídica entre los estados en materia penal y la necesidad de unificar los criterios jurídicos que se aplicaban en tales casos.

Se hace también necesario, aunque antes se apunto, el indicar que la Audiencia Nacional no es solamente un órgano perteneciente 
a la jurisdicción penal, aunque sea, ciertamente, su aspecto más conocido y divulgado. Dicha institución judicial tiene unas facetas muy importantes derivadas de que en la misma existen órganos judiciales pertenecientes tanto a la jurisdicción contencioso-administrativa, así como a la jurisdicción social. Con relación a la primera, debe tenerse presente la reforma propiciada por la Ley de 27 de diciembre de 1.956, reguladora de la Jurisdicción Contencioso-Administrativa, por la Ley 10/1.973, de 17 de marzo, al determinar que solo las disposiciones generales y los actos procedentes de altas instancias administrativas fueran enjuiciables directamente por el Tribunal Supremo, se propuso dotar de eficacia a la revisión jurisdiccional, cosa que en tales circunstancias no se lograba, toda vez que la Sala Tercera del Tribunal Supremo tenía una excesiva competencia en única instancia que entorpecía su funcionamiento, e impedía que el pronunciamiento judicial fuera próximo a la disposición o acto impugnado.

Por ello se creó dentro de la Audiencia Nacional un tribunal que conociera de las cuestiones cuyo mantenimiento en sede del Tribunal Supremo no aparecía suficientemente justificado, ya que sin quebrar el esquema orgánico del orden jurisdiccional contencioso-administrativo, ofrecía la ventaja de asegurar la función directiva que corresponde al Tribunal Supremo y, al mismo tiempo, suponía liberarlo del conocimiento de un gran numero de asuntos, ya que al conocer dicho nuevo tribunal de los actos procedentes de órganos administrativos de competencia nacional, tenía también el mismo carácter que determinaba dentro del ámbito de la jurisdicción penal, tanto su creación, como sus competencias, sin que ello supusiera un detrimento en el desarrollo de las funciones propias que competían a los órganos judiciales que integraban la Jurisdicción Contenciosa-Administrativa, y al mismo tiempo, sin que por ello se limiten tampoco las garantías que presidían y deben presidir su funcionamiento, especialmente a lo que atañe a los recursos procesales. Idénticos argumentos son extrapolables a la jurisdicción-social, y que justifican la creación de órganos de tal índole en el seno de la Audiencia Nacional.

Hoy en día, transcurridos cerca de veintiséis años desde su creación es indudable que puede llevarse a cabo una importante labor crítica sobre la misma, en paralelo al reconocimiento de sus virtudes, y sobre todo, del cometido realizado.

Olarieta Alberdi con relación al juicio valorativo de esta institución recoge diversas opiniones, citando a Lorca Navarrete afirma que la Audiencia Nacional fue «creada al amparo de una normativa de dudosa legitimidad democrática» y que sus evidentes concomitancias con el 


\section{La Audiencia Nacional}

Tribunal Central de lo Penal hicieron estallar las mismas críticas que éste recibiera en su día. En este sentido recoge las palabras del profesor Andrés de la Oliva el cual afirmó taxativamente en un artículo publicado por un semanario que «la Audiencia Nacional es antidemocrática de nacimiento», mientras que Peces-Barba titulaba otro: "La Audiencia Nacional: atentado a un derecho fundamental» haciendo referencia al derecho al juez natural.

Sin embargo, la posición actual mayoritaria es obvio que no identifica a la Audiencia Nacional con los tribunales del antiguo régimen, antes al contrario, se considera como un órgano judicial diferente o de nueva planta, tal y como se encuentra recogido en la Ley Orgánica 6/1.985, de 1 de julio, del Poder Judicial, el cual cumple la misión que legalmente le viene atribuida por su norma constitutiva, en plena conformidad con la Constitución de 1.978, y demás elementos legales que configuran la organización y el funcionamiento del poder judicial en un Estado de derecho, como es la España del siglo XXI.

Nadie puede dudar del ingente papel que han desempeñado este órgano judicial durante estos largos daños de experiencia democrática, en la lucha contra el terrorismo, y otras formas de delincuencia dentro del ámbito jurídico de su competencia, y el efecto saludable tanto para el funcionamiento de la Administración de Justicia, como para los ciudadanos de la existencia de una Institución como la que nos ocupa, que ha venido a llenar un vacío jurisdiccional, tanto en la jurisdicción contenciosa-administrativa, como en la de carácter social, donde ante el poder judicial no podía de manera adecuada, rápida y eficaz cubrir las necesidades jurisdiccionales que la sociedad y los ciudadanos reclaman.

Son no obstante, algunas las cuestiones que cabe criticar en los momento actuales con relación a su organización interna y su funcionamiento. Existen disfunciones mas que evidentes, que provocan el retraso en la tramitación de las causas, y en alguna medida surgen críticas con relación a la permanencia de los Jueces en los órganos que lo componen, y en alguna medida, su idoneidad. El estrellato de los jueces no es un efecto saludable para el funcionamiento de los órganos judiciales, pero probablemente es difícilmente evitable en esta categoría de Tribunales, sobre todos los de carácter unipersonal. Tampoco es una cuestión baladi, si la sociedad rechaza o no este tipo de actitudes personales, que a la postre parecen irrelevantes en función de la propia eficacia que demuestren los titulares y responsables de dichos Juzgados en el desenvolvimiento y desarrollo de sus competencias $\mathrm{y}$ atribuciones legales. 
Sin embargo, la situación en los momentos actuales lleva a efectuar una reflexión sobre el alcance de sus competencias, apareciendo como aconsejable la incorporación dentro de su seno de nuevos órganos judiciales, tal como sucedió no hace demasiados años con el Juzgado Central de lo Penal. Estos nuevos órganos serían por ejemplo:

A) El Juzgado Central de Vigilancia Penitenciaria, que velaría por el régimen penitenciario, valga la redundancia, y el cumplimiento de las penas de la masa reclusa sentenciada por la propia Audiencia Nacional.

B) Del mismo modo, se hace preciso igualmente la constitución de uno o varios Juzgados de Centrales de lo Civil, a los efectos de dar un tratamiento unitario a aquellos procedimientos donde existan múltiples afectados, o no por la naturaleza o circunstancias del procedimiento no pueda circunscribirse a una provincia o circunscripción determinada, aunque dicha situación pueden quedar paliada en parte por los nuevos Juzgados de los Mercantil.

En la actualidad, la Audiencia Nacional, como parte integrante del Poder Judicial se encuentra regulada además en los artículos 62 y siguientes de la citada Ley Orgánica del Poder Judicial, donde se determina la competencia que posee cada uno de los órganos judiciales que la integran.

Así, la Sala de lo Penal conocerá en única instancia, del enjuiciamiento de las causas por los siguientes delitos, así como de los que sean conexos de los mismos:

A) Delitos contra el titular de la corona, su consorte, su sucesor, altos organismos de la nación y forma de gobierno.

B) Falsificación de moneda, delitos monetarios y relativos al control de cambios.

C) Defraudaciones y maquinaciones para alterar el precio de las cosas que produzcan o puedan producir grave repercusión en la seguridad del trafico mercantil, en la economía nacional o perjuicio patrimonial en una generalidad de personas en el territorio de mas de una audiencia.

D) Trafico de drogas o estupefacientes, fraudes alimentarios y de sustancias farmacéuticas o medicinales, siempre que sean cometidos por bandas o grupos organizados y produzcan efectos en lugares pertenecientes a distintas audiencias.

E) Delitos cometidos fuera del territorio nacional, cuando conforme a las leyes o a los tratados corresponda su enjuiciamiento a los tribunales españoles. 


\section{La Audiencia Nacional}

Asimismo, es competente para el conocimiento:

A) De los procedimientos penales iniciados en el extranjero, de la ejecución de sentencias dictadas por tribunales extranjeros o del cumplimiento de pena de prisión impuesta por tribunales extranjeros, cuando en virtud de un tratado internacional corresponda a España la continuación de un procedimiento penal iniciado en el extranjero, la ejecución de una sentencia penal extranjera o el cumplimiento de una pena o medida de seguridad privativa de libertad.

B) De las cuestiones de cesión de jurisdicción en materia penal derivadas del cumplimiento de tratados internacionales en los que España sea parte.

C) De los procedimientos judiciales de extradición pasiva, sea cual fuere el lugar de residencia o en que hubiese tenido lugar la detención del presunto extradito.

D) De los recursos que se interpongan contra las sentencias y demás resoluciones de los juzgados centrales de instrucción.

En el ámbito de la jurisdicción contencioso-administrativa la Sala correspondientes conocerá en única instancia de los recursos contra disposiciones y actos emanados de los ministros y de los secretarios de estado, salvo que confirmen en vía administrativa de recurso o en procedimiento de fiscalización o tutela los dictados por órganos o entidades distintos, cualquiera que sea su ámbito territorial.

Y finalmente, en lo que atañe a la jurisdicción social, la Sala de lo Social de la Audiencia Nacional conocerá en única instancia:

A) De los procesos especiales de impugnación de convenios colectivos cuyo ámbito territorial de aplicación sea superior al territorio de una comunidad autónoma.

B) De los procesos sobre conflictos colectivos cuya resolución haya de surtir efecto en un ámbito territorial superior al de una comunidad autonoma.

Con independencia de ello, cabe indicar que en la Audiencia Nacional existe una expresa adscripción o destacamento de la Fiscalía, así como de la Abogacía del Estado. 